\title{
Eco-dynamics of territorial systems: an Emergy Evaluation through time
}

\author{
A. C. I. Pizzigallo ${ }^{1}$, V. Niccolucci ${ }^{1}$, A. Caldana ${ }^{2}$, M. Guglielmi ${ }^{2}$ \\ \& N. Marchettini ${ }^{1}$ \\ ${ }^{I}$ Department of Chemical and Biosystems Sciences, University of Siena, \\ Italy \\ ${ }^{2}$ Provincial Administration of Modena, Italy
}

\begin{abstract}
Environmental sustainability requires ongoing care from the public administration to improve people's quality of life, without jeopardizing the natural resources upon which human activities are founded. The aim of this paper is to present an environmental sustainability assessment of a local territorial system based on a thermodynamic method: Emergy Evaluation.

Emergy Evaluation is able to compare the value of human and natural systems on a common basis: the quantity of solar energy directly and indirectly required for a process that represents the memory of all the energy and matter that the biosphere used up to make a product available or to support a territorial system. The use of Emergy enables the calculation of some indicators (such as Environmental Loading Ratio, Emergy Yield Ratio, Emergy Density, Emergy Investment Ratio), in order to give a systemic and holistic picture of the territorial system from a sustainability point of view. By Emergy approach it was possible to distinguish if the territory plays the role of transformer of raw materials or a final consumer of refined materials.

The paper proposes and compares two scenarios realized in different years (1997 and 2003), in order to monitor and overview the evolution of a local system. The territorial system analyzed is the Province of Modena which is located in the north of Italy and is characterized by dynamic productive sectors, such as food, steel and ceramic industries, and an important population density (242 inhabitans $/ \mathrm{km}^{2}$ ).

Results show an increasing trend of all emergy flows and indicators quite typical for an industrialized country. This is especially due to the higher request for goods and services from outside the boundaries of the system. Nevertheless, the total renewable flow is increased to $7.3 \%$ thanks to a higher use of energy from renewable sources, i.e. hydro and co-generation. This is due to the attention that the Administration has devoted in the last ten years.

Keywords: time series emergy evaluation, environmental sustainability, thermodynamics, ecodynamics.
\end{abstract}




\section{Introduction}

The biosphere and its systems, both ecological and humans, are sustained by steady inflows of energy and matter. In default of these flows, systems cannot build order and their conditions might change in a lower quality state. Emergy Evaluation can evaluate these inflows of energy and matter, monitoring their change in time, to study human systems and their dynamics, from the relationships between human society and the environment. The suitability of Emergy Evaluation in understanding the relationships between humandominated systems and the biosphere is already well-known [1].

Human society feeds on quantities of energy and materials that flow through and within the boundaries of a territorial system; it draws energy directly from the environment or indirectly in the form of goods purchased from the outer economies. Energy inputs with different forms and quality (low or high quality) constantly supply local activities, and productive/transformation processes in order to provide products and services for local communities or as sources for external systems (export).

Consequently, using energy flows to study a territorial system seems to be necessary to provide a common value basis for evaluating the flows in the environmental and socioeconomic system [2]. Moreover, by providing a tool (Emergy) able to monitor these energy and matter flows throughout time, it can be useful for the decision-making process as providing valuable analysis to understand the system [3].

The aim of this paper is to present an environmental sustainability assessment of a local territorial system (Province of Modena) based on Emergy Evaluation. The evaluation is based on the comparison of two scenarios collected in two different years, in 1997 and 2003. This approach is still quite rare, but it is really important in order to monitor and overview the evolution of a local system. It is well-known that environmental sustainability requires an ongoing care from public administration to improve the people's quality of life without compromising the environment. This analysis in time series represents a novelty, because it considers the changes of residents' behaviour in time, considering mainly the natural resources upon which human activities are founded. Local administration pays attention to the environmental issues: since the ' 90 s public authorities of the Province of Modena have begun, within the system they manage, a sustainability pattern, in order to promote and to emphasize the identity of their territory [4]. The knowledge of the system where a community lives is an important step to face the issues of sustainable development.

Emergy Evaluation has already been used in the past for different kinds of territorial systems, such as a national system (see e.g. [5,6]), a sub-national system (see e.g. [7]), and a productive/transformation system (see e.g. [8-11])

Starting from the analysis of the well-known Emergy indicators (e.g. Environmental Loading Ratio, Emergy Investment Ratio, Emergy Yield Ratio) and Emergy flows (e.g. renewable, R; non-renewable, N; imported energy and goods, F), we focus our attention on the ability of the system to feed its population, and how the system is able to transform energy and matter flow of 
low quality or grade into a higher one for itself or for export to the global economy. Moreover, we will pay attention to the goods and services that are imported and transformed with respect to those imported and consumed within the system. For this reason, we will consider two scenarios for each year of the analysis performed: both these scenarios will compare the total emergy flow that feeds the system with respect to the total emergy flow locally consumed in 1997 and in 2003.

Results highlight that the flows through time are increased by about $42 \%$; more deeply, the flow of renewable resources is increased by about $7.3 \%$ : this is due to the conspicuous increase of electric power consumption, resulting from local production of renewable sources, such as hydro-electric and cogeneration. In the period 1997-2003, the reliance on the external inflows of energy and matter has increased within the period under analysis; the imported goods and services within the boundaries of the system have increased by about $52 \%$.

Conclusions underline how the territorial system is becoming more local energy-consuming over the time considered. Future development of Modena and its dynamics need to be aimed to the optimization of energy use inside the productive texture of the Province.

\section{Materials and methods}

\subsection{The case study: the Province of Modena}

The Province of Modena, located in the North of Italy, is the territory under study. It occupies an area of $2,690 \mathrm{~km}^{2}$ that is quite heterogeneous with $48 \%$ level land, $17 \%$ hill and 35\% highland. In 2003 the population was estimated to be 651,996 inhabitants with a density of 242 inhabitants $/ \mathrm{km}^{2}$, higher than the national average value (190 inhab. $\left./ \mathrm{km}^{2}\right)$. The demographic trend shows an annual growth of $+1 \%$ in the last ten years. Administratively the territory is divided into 47 municipalities.

Modena is one of the most industrialized Italian provinces with a dynamic economy based on trade and transformation of raw materials. The main sectors are handmade manufactures, e.g. ceramics, that generate $80 \%$ of the total Italian ceramics production, and metalworking. Other minor production sectors are textiles and clothing, biomedicals and disposable, agroalimentary productions, especially devoted to cereals (wheat and maize), soya, green stuff and fruits (quite famous are the cherries of Vignola). Modena is the fourth Italian province in 2003 according to the GPD per person ranking as suggested by the Italian Statistic Bureau [12].

The analysis presented in this paper is based on Emergy Evaluation through time in order to compare the local situation during the period 1997-2003.

\subsection{Emergy evaluation}

Emergy was introduced by H.T. Odum in the ' $80 \mathrm{~s}$ as a tool for environmental (but not only environmental) accounting $[1,2]$. On the basis of a thermodynamic 
hierarchy of energy, starting from solar energy, Odum's research has provided a measure of the environmental work necessary to generate an item or a flow.

This methodology is organised as a top-down approach, in which systems diagrams of processes are drawn in order to identify and account for all inputs and outputs from processes, that are evaluated on a common basis, i.e. equivalent solar energy [1].

Emergy is defined as the quantity of solar energy directly or indirectly necessary to sustain a given system and its level of organization. The emergy of all inputs to a system is calculated in terms of solar emjoules (sej) by means of suitable conversion factors called transformities (expressed in sej/J), or specific emergy (expressed in sej/unit) [2]. The total emergy necessary for a system (U) is classified into local renewable $(\mathrm{R})$, local non-renewable $(\mathrm{N})$ and imported from outside (F). This last emergy flow, also known as purchased inputs, can be divided into two main flows, the energy imported flow (F1), and the goods and services imported flow (F2). The last one (F2) can be divided in two main flows that represent inputs locally consumed (F2c) and inputs locally transformed (F2t). The first one is referred to the fraction of the total flow that enters the system and it is directly consumed inside by local communities, while the second one includes the fraction that considers the transformation of raw materials into secondary products able to feed on, in a given shares, external systems as services and goods exported. This distinction is quite important because while the former is related to the direct consumption of external inflows by local residents, the latter is related to the purchased inflows transformed inside the system and assigned for export. In this paper we will consider two scenarios for each year of analysis. This different view of the purchased inputs raises three different questions: how much is the total emergy flow that feeds the system (U), how much the territorial system needs and consumes within its boundaries (U'), and how much is transformed and directly exported to external systems (U-U')? Indeed, we will consider two plans of the Province of Modena: the first one based on the total emergy flow that feeds the whole system (U), and the second one based on the consumed emergy flow of the system (U').

Starting from this distinction, it is possible to calculate a set of sustainability indicators that can be used to assess the relative sustainability of a system: in this context, we measure the effort that natural systems must exert in order to produce an item after it has been consumed [2,5]. The Environmental Loading Ratio (ELR) is the ratio of purchased (F) and non-renewable local emergy (N) to renewable environmental emergy $(\mathrm{R})$. A high value of the ELR indicates a lack of proportion between the use of non-renewable resources with respect to renewable ones, so that environmental cycles are overloaded. The Emergy Yield Ratio (EYR) is the ratio of total emergy $(\mathrm{R}+\mathrm{N}+\mathrm{F})$ supporting the system to the emergy of the inputs from the economic sector (F) (i.e. not provided for free by the environment). It indicates if a process can compete in supplying a primary energy source for an economy. The Emergy Investment Ratio (EIR) is the emergy of purchased inputs (F) divided by local emergy, both renewable and non-renewable $(\mathrm{N}+\mathrm{R})$. A high level of EIR represents a sort of fragility of the system because of its dependence on inputs from other economic systems. The 
Emergy Flow Density (ED) is given by the emergy flow $(\mathrm{R}+\mathrm{N}+\mathrm{F})$ supporting a system divided by its area. If this ratio is high, a large quantity of emergy is used in a certain area: this can mean a high stress to the environment, and points out the land surface as a limiting factor for future development.

Emergy Evaluation in time series was applied to the Province of Modena in order to show a resource-based geography in terms of the use of ecosystems goods and services, and to calculate quali-quantitative indices and ratios for future environmental and economic policies at the local level.

\section{Results and discussion}

\subsection{The Province of Modena in the 2003}

The Province of Modena is a high energy-consuming territorial system; its reliance on energy/matters inflows is determined by the high population density, high service industry and, more in general, a high degree of economic sector development. The evaluations of these emergy flows used transformities that were based on the global empower base of $15.83 \times 10^{24} \mathrm{sej} / \mathrm{yr}[13]$.

Table 1 shows the results of the Province of Modena in 2003, as well as in 1997. The total emergy flow is equal to $6.64 \times 10^{22} \mathrm{sej} / \mathrm{yr}(\mathrm{U})$, and the consumed emergy flow is equal to $4.88 \times 10^{22} \mathrm{sej} / \mathrm{yr}$ (U'). This results highlight that about $27 \%$ of the total emergy flow that sustains Modena is transformed inside its boundaries and directly transferred as an export outflow to outer systems.

These results point out that there is a high use of external resources with respect to those endogenous ones, with a ratio of 10 to 1 . Modena and its productive/transformation system are deeply dependent on the external systems in providing raw materials inflows. Moreover, non-renewable flows $(99.06 \%)$ are higher than the renewable ones $(0.94 \%)$. Most of the non-renewable resources come from external systems $(91.3 \%)$, while the local non-renewable emergy flow comes from ore-mining, especially for ceramics and housing productions.

The demand for electric power is mainly satisfied by hydroelectrics (52\%), partially considered as a renewable energy source, by cogeneration $(37 \%)$, and by an energy-from-waste plant $(10.8 \%)$, that determines an important and valuable energy reclaimation, even if it cannot be considered totally as a renewable source.

Considering the twofold scenarios in 2003, the ELR increases by about $36 \%$. As shown in table 1, this indicator suggests that inside this territorial system there is a high overexploitation of non-renewable resources with respect to those renewable. The EYR is very close to 1 ; this result underlines the high fragility of the system, tied to a massive import of energy and matter from outside. The EIR is equal to 7.45 , because the total purchased inputs $(\mathrm{F})$ reach the percentage $91.3 \%$. The emergy density is a very high flow equal to $2.47 \times 10^{13} \mathrm{sej} / \mathrm{yr}$; this value decreases to $1.81 \times 10^{13} \mathrm{sej} / \mathrm{yr}$ in the second scenario. The emergy per person is equal to $1.02 \times 10^{17} \mathrm{sej} / \mathrm{inh}$ ab.: it is readable as per capita consumption of resources, rather than an availability of resources. 


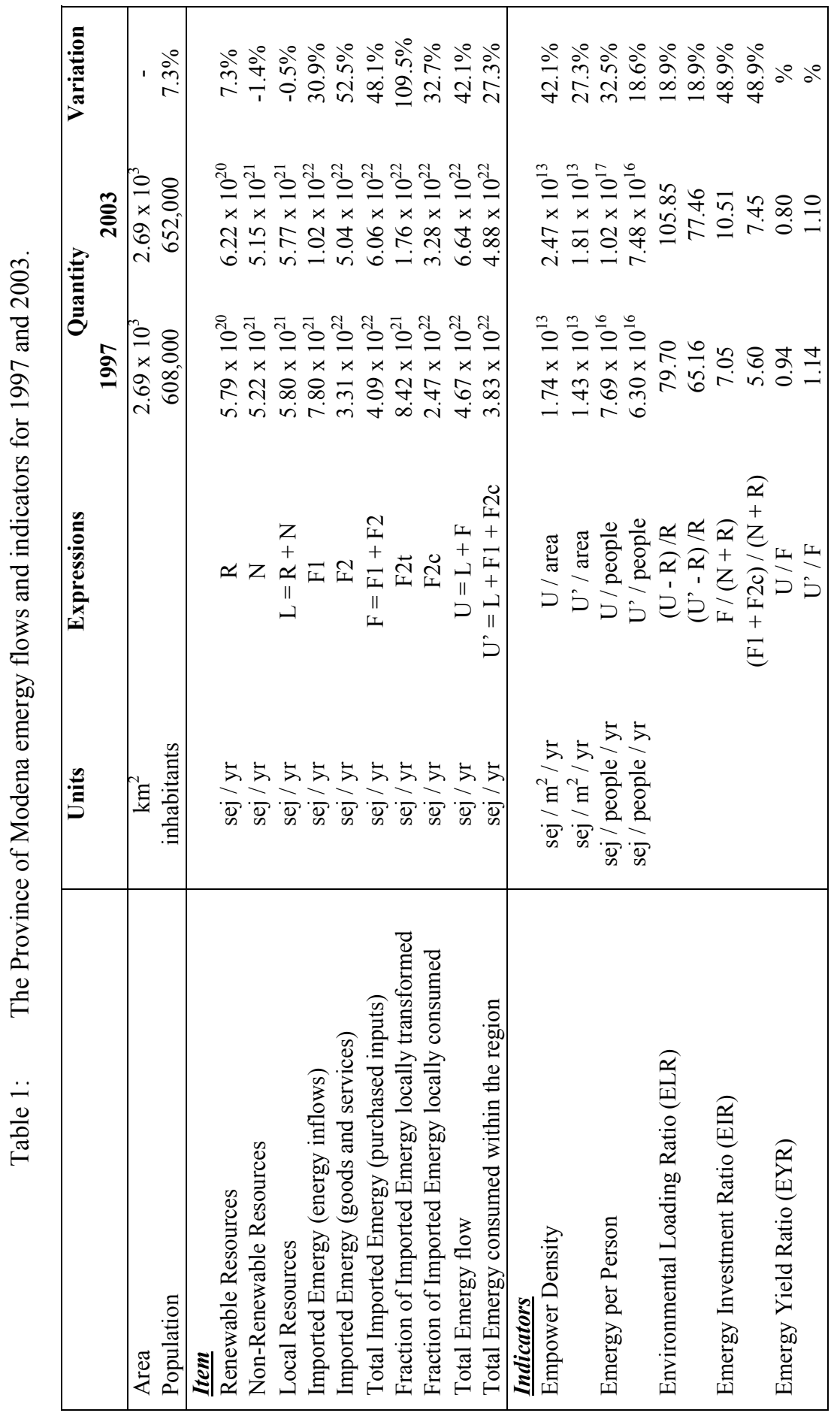

WIT Transactions on Ecology and the Environment, Vol 106, (C) 2007 WIT Press www.witpress.com, ISSN 1743-3541 (on-line) 


\subsection{The Province of Modena in 1997 and in 2003: a compared analysis}

The Province of Modena was already analysed in 1997 by Emergy Evaluation [4]. The increase in the global emergy base of reference to $15.83 \times 10^{24} \mathrm{sej} / \mathrm{yr}$ $[13,14]$ changes all the unit emergy values which directly and indirectly are derived from the value of global annual empower. For this reason, the analysis performed in 1997 was updated with new transformities, in order to make the comparison between the two analyses.

From 1997 to 2003, the total emergy flow (U) is raised by about 42\%; more deeply, the renewable flows are raised by about $7.3 \%$. In spite of this result, the share of renewable resources with respect the total emergy flow is decreased from $1.24 \%$ in 1997 to $0.94 \%$ in 2003 . The non-renewable resources are decreased by about $1.4 \%$, because the soil erosion due to ore-mining is diminished. The energy imported flow (F1) is increased by about $31 \%$; this increase is due to the electric power and natural gas consumption that in these years rises at a great rate. There is no change in the weight of the energy purchased inputs with respect to the total emergy flow between 1997 and 2003. The goods and services imported flow (F2) is increased by about $52 \%$. This result determines the increase of the weight of this flow with respect to the total emergy flow (U): it rises from $70 \%$ to $75 \%$.

The ELR highlights the tendency of the territorial system to use a big amount of non-renewable resources, higher than the renewable ones. The socioeconomic dynamics and the deep increase of goods and services imported contributed to this trend. The EYR has remained steady throughout the period under analysis. The EIR has increased by about 50\%. This dynamic is explained by the increased reliance of the territorial system on the external resources. The emergy per person has increased by about $32 \%$; this result is especially determined by the higher population density in 2003 with respect its value in 1997.

At the end, we point out that in 1997 the flow $U$ ' is equal to $82 \%$ of $U$, while in 2003 the percentage has decreased to $73 \%$. This means that the Province of Modena has increased its ability to transform the flows directly exported. Although a great amount of the total emergy flow is exported (26\% in the 2003), it constitutes an essential source for its economy.

\section{Conclusions}

This paper presented an environmental sustainability analysis based on Emergy Evaluation. This study aimed to give an important tool to public administration, in order to perform a sustainability pattern of a territorial system. The analysis, performed in time series (1997-2003), represents a novelty for a sub-national system assessment. It demonstrates that overall the Province of Modena continues to be a system highly dependent on external resources. The lower use of local resources, especially renewables, determines a higher environmental loading relative to the national average value. 
In this time series analysis, we point out that the Province of Modena has increased its ability to transform the flows directly exported. This result is shown by the comparison of the total emergy flow that feeds the Province of Modena (U), and the total emergy flow consumed by the same territorial system.

This method supplies sustainability indicators to the policy makers, in the effort to analyse, evaluate, compare and classify the area under study and to suggest alternative ways to the policy makers.

\section{References}

[1] Odum, H.T. Self organisation, transformity and information. Science, 242, pp. 1132-1139, 1988.

[2] Odum, H.T. Environmental Accounting. Emergy and Environmental Decision Making. John Wiley and Sons. New York, 1996.

[3] Tilley, D.R., National metabolism and communications technology development in the United States, 1790-2000. Environment and History: 12, 165-90, 2006.

[4] Bastianoni, S., Porcelli, M., Tiezzi, E., Sustainable development models for the analysis of the Province of Modena (Italy). Ecosystems and Sustainable Development II, Advances in Ecological Sciences, (eds) Brebbia, C.A., Usó J.L., WIT press, Southampton (UK), pp.185-193, 1999.

[5] Ulgiati, S., Odum, H.T., Bastianoni, S., Emergy analysis, environmental loading and sustainability. An emergy analysis of Italy. Ecological Modelling, 73, 1994.

[6] Campbell, D.E., Brandt-Williams S.L. and Meisch, M.E.A., Environmental accounting using emergy: evaluation of the state of West Virginia. U.S.EPA, Narragansett, RI, 2005.

[7] Pulselli, R.M., Pulselli, F.M., Rustici, M., Emergy accounting of the Province of Siena: Towards a thermodynamic geography for regional studies, Journal of Environmental Management, In Press.

[8] Vassallo, P., Bastianoni, S., Beiso, I., Ridolfi R., Fabiano M., Emergy analysis for the environmental sustainability of an inshore fish farming system, Ecological Indicators, 7, 2, Pages 290-298, 2007.

[9] Bastianoni, S., Marchettini, N., Panzieri M., Tiezzi E., Sustainability assessment of a farm in the Chianti area (Italy), Journal of Cleaner Production, 9, 4, Pages 365-373, 2001.

[10] Pizzigallo, A.C.I., Granai, C., Borsa, S., The joint use of LCA and emergy evaluation for the analysis of two Italian wine farms, Journal of Environmental Management, In Press.

[11] Borsa, S., Marchettini, N., Pizzigallo, A.C.I., Pulselli, F.M., Thermodynamic optimisation of the use of natural resources: an agroalimentary production in a Chianti farm (Italy). Ecosystems and Sustainable Development V, Advances in Ecological Sciences, (eds) Tiezzi, E., Brebbia, C.A., Jørgensen, S.E., Almorza Gomar, D., WIT Press, Southampton, UK, pp. 23-30, 2005. 
[12] ISTAT. Atlante della competitività delle province italiane. Ufficio Statistico Camera di Commercio Provincia di Modena, Elaborazione dati Istituto G. Tagliacarne su dati ISTAT, 2003. Available online on $\mathrm{http} / / / \mathrm{www}$. unioncamere.it/Atlante/selreg frame800.htm

[13] Odum H.T., Brown M.T., Brandt-Williams S. Introduction and Global Budget, Folio \#1. Handbook of Emergy Evaluation. Center for Environmental Policy, University of Florida, Gainesville, USA, 2000.

[14] Odum H.T. Emergy of Global Processes, Folio \#2. Handbook of Emergy Evaluation. Center for Environmental Policy, University of Florida, Gainesville, USA, 2000. 